\title{
COMPARATIVE STUDY OF THE SURFACE ROUGHNESS OF ORMOCER-BASED AND CONVENTIONAL COMPOSITES
}

\author{
ESTUDO COMPARATIVO DA RUGOSIDADE SUPERFICIAL ENTRE \\ COMPÓSITOS À BASE DE ORMOCER E SISTEMAS MONOMÉRICOS \\ TRADICIONAIS
}

\author{
Leonardo Gonçalves CUNHA, DDS, MSc \\ Graduate Student, Dental Materials Area, Piracicaba School of Dentistry, UNICAMP, Brazil. \\ Roberta Caroline Bruschi ALONSO, DDS, MSc \\ Graduate Student, Dental Materials Area, Piracicaba School of Dentistry, UNICAMP, Brazil. \\ Paulo Henrique dos SANTOS, DDS, MSc \\ Graduate Student, Dental Materials Area, Araçatuba School of Dentistry, UNESP, Brazil. \\ Mário Alexandre Coelho SINHORETI, DDS, MSc, PhD \\ Associate Professor, Dental Materials Area, Piracicaba School of Dentistry, UNICAMP, Brazil.
}

\begin{abstract}
$T$ he aim of this study was to evaluate the surface roughness of two Ormocer-based resin composites before and after mechanical toothbrushing. The study compared the brands Admira and Definite with composites based on conventional monomer systems (Bis-GMA, Bis-EMA, UEDMA e TEGDMA), Z250 and A110. Eight samples of each material with $4 \mathrm{~mm}$ in diameter and $2 \mathrm{~mm}$ in height were prepared using a metallic mold. After 24 hours they were polished and examined with a profilometer for measurement of the initial surface roughness $(\mathrm{Ra}, \mathrm{mm})$ before mechanical toothbrushing (30,000 cycles). After toothbrushing, the samples were taken to the profilometer once again to check the final surface roughness. The results were submitted to ANOVA and Tukey test (5\%). The Admira composite presented a higher mean of surface roughness before toothbrushing $(0.132 \mathrm{~mm})$, with a statistical difference from the composite A1 $10(0.082 \mathrm{~mm})$. Definite $(0.110 \mathrm{~mm})$ and Z250 $(0.105 \mathrm{~mm})$ composites showed no differences between themselves or among the other composites. No statistical differences were observed after toothbrushing between the composites Definite $(0.178 \mathrm{~mm}), \mathrm{Z} 250(0.187 \mathrm{~mm})$, Admira $(0.181 \mathrm{~mm})$, and A110 $(0.193 \mathrm{~mm})$. All composites showed a statistically significant increase in the surface roughness after toothbrushing.
\end{abstract}

UNITERMS: ORMOCER; Resin composite; Surface roughness.

\section{INTRODUCTION}

Light activated composites used in the restoration of cavities in stress-bearing posterior teeth have increased rapidly in the recent years. Besides, the ability to bond to hard tooth tissues mediated by the adhesive systems features the advantages of good esthetics and less expensive cost when compared to cast gold inlays and ceramic inlays. However, the insufficient material properties limit the success of composite restorations in posterior teeth ${ }^{7}$. Inadequate resistance to wear resulting in a loss of anatomic form, fracture within the body of the restorations and margins, and marginal leakage due to polymerization shrinkage were often cited as being the most common causes of failure in posterior composite restorations ${ }^{8}$.
Abrasion of resin composite, caused by long-term clinical use in the oral environment, includes both occlusal wear and toothbrush abrasion. Occlusal wear of the composite material is produced by masticatory stress. Toothbrush abrasion, which is another important phenomenon as regards the wear characteristics of composites, is undesirable due to esthetic and biologic disadvantages, because daily toothbrushing with dentifrice leads to changes in the surface condition of any composite material. Rough surfaces of the composite material caused by toothbrushing are known to increase the accumulation of dental plaque and decrease the gloss of the composite restoration ${ }^{12}$. Surface texture measurements can facilitate the understanding of how a material will stain or wear in vivo. An important factor in the clinical performance of a material is 
how it responds to oral hygiene measures such as toothbrushing

${ }^{14}$. If the composite material has a surface roughness of 0.2ìm or more, dental plaque accumulation may occur, increasing the risk to both caries and periodontal inflammation ${ }^{2}$. Cannon et al ${ }^{3}$ found that toothbrushing may substantially abrade poorly finished surfaces of composites. The type of composite material is especially important from a clinical standpoint, because the type and composition of the current composites introduced as restorative materials differ widely.

There are a great number of resin composites based on conventional monomer systems such as Bis-GMA, UEDMA, TEGDMA, and Bis-EMA. In addition to these types of composite material, which are based on cross-linking dimethacrylates and inorganic fillers, a new type of inorganicorganic hybrid dental material, known as Ormocers, has been developed since $1991{ }^{9}$. The synthesis of this composite was developed by the use of special substitutes to create a complex structure, formed by only one polymerizable double bond and alkoxy group, responsible for the formation of the $\mathrm{Si}-\mathrm{O}-\mathrm{Si}$ structure, converting the monomeric precursors into a polymeric inorganic condensate via sol-gel processing. A considerable widening of the adjustable properties is obtained through the possible incorporation of different fillers in the Ormocer composite (up to $67 \mathrm{vol} \%$ ). The addition of fillers may bring an improvement of the mechanical and physical properties of this class of composites, such as small abrasion rate, low water absorption, and low water solubility ${ }^{15}$.

The literature presents few studies on the Ormocer based composites and their beneficial physical and mechanical properties. Therefore, the aim of this study was to determine the toothbrushing surface roughness of two Ormocer restorative materials compared to two traditional composites, which comprise the group of composites that can be considered as the current standard material for clinical use.

\section{MATERIAL AND METHODS}

The materials used in this study are shown in Table 1. Eight samples of each composite resin were constructed at $23 \pm 1^{\circ} \mathrm{C}$ and $50 \pm 5 \%$ relative humidity, using a metallic die $(4 \mathrm{~mm}$ diameter and $2 \mathrm{~mm}$ height), in a total of 32 samples.

A polyester strip was placed on the bottom of the cavity and the composite resin was inserted in a single portion and compacted with a ward condenser \#2. A polyester strip and a thin glass slab were placed over the composite under a load of $200 \mathrm{~g}$ to remove excess material. After removal of the glass slab, the samples were light-cured for 40s with a curing unit XL 1500 (3M Dental Products, St. Paul, MN, USA), with an output of approximately $500 \mathrm{~mW} / \mathrm{cm}^{2}$. The composite resin samples were then removed from the die and stored at $37^{\circ} \mathrm{C}$ and $100 \%$ relative humidity.

After 24 hours, the specimens were submitted to a finishing process using the Sof-Lex system (3M Dental Products, St. Paul, MN, USA) on a low-speed handpiece, without water cooling, according to the manufacturer's instructions. The following discs were used in sequence: coarse, medium, fine, and superfine, each for 40 seconds. The samples were stored at $37^{\circ} \mathrm{C}$ and $100 \%$ relative humidity until the first analysis of surface roughness, carried out after 24 hours.

The specimens were individually positioned in a Surfcorder SE 1700 profilometer (Kosakalab, Japan) to verify the roughness ( $\mathrm{Ra}$ ) values of the surfaces submitted to the finishing procedure. Three readings were made on each surface using a stylus tip ( $2 \mu \mathrm{m}$ in diameter). Each reading was obtained after turning the specimen $120^{\circ}$. The extension of each reading was $2.85 \mathrm{~mm}$, using a cut-off of $0.25 \mathrm{~mm}$. After this first analysis, the specimens were stored again under the same conditions before mechanical toothbrushing.

A toothbrushing machine (Equilabor, SP, Brazil) that can brush eight specimens at the same time was used. A Colgate Classic toothbrush (Colgate, SP, Brazil) was used in this test,

TABLE 1- List of composites used, manufacturers, composition and batch number

\begin{tabular}{|c|c|c|c|}
\hline Composite & Manufacturer & $\begin{array}{l}\text { Classification } \\
\text { (filler \%v) }\end{array}$ & Composition \\
\hline
\end{tabular}

3M Dental Products

Small Particles

$(60 \% \mathrm{v})$

A110

3M Dental Products

Microfilled

$(40 \% \mathrm{v})$

Admira Voco $\begin{array}{ll}\text { Definite Degussa } & \text { Hybrid } \\ & (56 \% \mathrm{v})\end{array}$

$\begin{array}{ll}\text { Definite Degussa } & \text { Hybrid } \\ & (56 \% \mathrm{v})\end{array}$
Small Particles

$(60.2 \% \mathrm{v})$
Bis-EMA, UEDMA, Bis-GMA, Zirconia Silica Synthetic Filler $(0.6 \mu \mathrm{m})$

Bis-GMA, TEGDMA, aluminum oxide, silane, organic filler and silica $(0.04 \mu \mathrm{m})$

ORMOCER, barium glass and silica $(1-1.5 \mu \mathrm{m})$
ORMOCER, aliphatic and aromatic dimethacrylate, glass ceramic filler $(0.7 \mu \mathrm{m})$ 
with a compact head and soft nylon bristles with hexagonal sections and rounded edges. The head of the toothbrush was composed of 36 tufts containing, on average, 53 bristles each, in a total area of $360 \mathrm{~mm}^{2}$. The head was sectioned with a tungsten carbide bur and fixed in the toothbrush holder device of the machine using Super Bonder (Loctite, SP, Brazil) fast setting adhesive. The tufts of the toothbrush head were fixed perpendicular to the specimen surface. Each toothbrush was used to brush only one specimen. The specimens were fixed in an orifice of a plastic plate $(47 \mathrm{~mm}$ long, $20 \mathrm{~mm}$ wide and $2.5 \mathrm{~mm}$ thick). The assembly was positioned in the metallic canister of the toothbrushing machine.

Six grams of Sorriso dentifrice (Sorriso, SP, Brazil) containing calcium carbonate (mean particles $6.5 \mu \mathrm{m}$ ) as an abrasive were weighed on a Chyo JK-180 Chyo, Japan) precision scale and put into the metallic canister together with $6 \mathrm{ml}$ of distilled water. The polished surface of each specimen was submitted to linear toothbrushing movements across the specimens, at a speed of 250 cycles per minute, considering a double pass of the brush head over the surface, for two hours, in a total of 30,000 cycles per specimen. The test was made under a load of $200 \mathrm{~g}$, used to simulate the load of oral hygiene procedures in a temperature and humidity controlled room. After mechanical toothbrushing, the specimens were removed from the machine, washed in tap water, and stored at $37^{\circ} \mathrm{C}$ and $100 \%$ relative humidity.

After the mechanical toothbrushing test, the same surface of each sample was submitted to a new reading of surface roughness in the same manner as the first reading. New samples were constructed and polished for each composite used. The respective samples of each material tested after toothbrushing were analyzed through scanning electron microscopy (LEO VP 435, Germany) using an acceleration voltage of $15 \mathrm{kV}$ and 2500x magnification.

The data were analyzed with ANOVA and comparisons between pairs of means between the test conditions for each composite were performed using the Tukey test at a $95 \%$ confidence level.

\section{RESULTS}

Table 2 shows the mean values of surface roughness for each composite resin and indicates that the mechanical toothbrushing process significantly increased the roughness of all materials tested. For Admira, the increase in surface roughness (from $0.1321 \mathrm{~mm} \pm 0.0072$ to $0.1810 \mathrm{~mm} \pm 0.0138$ ) after toothbrushing was the smallest among the composites, with a percentage increase of $37 \%$. For Definite and Z250, the values were 62 and 77\%, respectively. The A110 composite was the material with the highest difference in surface roughness (from $0.0823 \mathrm{~mm} \pm 0.0039$ to $0.1931 \mathrm{~mm} \pm 0.0236$ ) after toothbrushing, with an increase of $134 \%$. Figures 1-4 demonstrate the surface of the materials tested before and after toothbrushing.

Table 3 shows the mean values of surface roughness for the materials employed. Before toothbrushing, no statistical difference was found between the Z250 and Definite composites and in comparison with the other two composites used ( $\mathrm{p}>0.05$ ). The Admira composite presented values of surface roughness that were statistically superior to the composite A110 $(\mathrm{p}<0.05)$ before the mechanical toothbrushing test. After mechanical toothbrushing, no statistical differences were found between the materials used $(\mathrm{p}>0.05)$.

\section{DISCUSSION}

The surface roughness of a material is the result of the interaction of multiple factors associated with the filler (type, size and distribution of the particles), type of resinous matrix of the material and consequent degree of cure reached, and of the efficient bond of filler and matrix at the interface 5 . Other parameters such as type of polishing accomplished and lightcuring method are also of fundamental importance to the values of surface roughness. However, they were standardized and the different tested materials were submitted to the same parameters as for the polishing type / light-curing method.

Both resin matrix and filler particle type or content are thought to affect surface condition after toothbrushing because of selective abrasion of the resin matrix and the dislodgment of filler particles caused by long-term use ${ }^{12}$. The Ormocer based composites possess a modified organic matrix, formed by monomers with a single polymerizable end. The other end is formed by an alkoxy group, resulting in an inorganic area, bonded to other monomers by a chemical reaction of condensation, converting the monomer precursors in a polymeric inorganic condensate, via sol-gel processing, creating a complex structure with the formation of the $\mathrm{Si}-\mathrm{O}-\mathrm{Si}$ chain in the inorganic area of the polymer. The combination of this organic-inorganic matrix and filler particles in high concentrations (superior to $67 \% \mathrm{vol}$ ) would generally provide physical and mechanical properties superior to those of conventional composites, advantageous to the Ormocer based composite $^{9-15}$.

However, this modification of the matrix could bring the disadvantage of a larger surface roughness of the Ormocer

TABLE 2- Comparative mean values $(\mathrm{Ra}, \mu \mathrm{m})$ of surface roughness for all composites

\begin{tabular}{lcc}
\hline & Before & After \\
\hline Admira & $0.132(0.007) \mathrm{a}$ & $0.181(0.013) \mathrm{a}$ \\
A110 & $0.082(0.003) \mathrm{b}$ & $0.193(0.023) \mathrm{a}$ \\
Definite & $0.110(0.006) \mathrm{ab}$ & $0.179(0.004) \mathrm{a}$ \\
Z250 & $0.105(0.006) \mathrm{ab}$ & $0.188(0.001) \mathrm{a}$ \\
Mean Value & 0.107 & 0.185 \\
\hline
\end{tabular}

Mean values followed by different small letters in the column are statistically different from each other as demonstrated by the Tukey test at the level of $5 \%$. The comparison of the mean values in the row is significant at the level of $5 \%$. ( ) Standard Deviation 

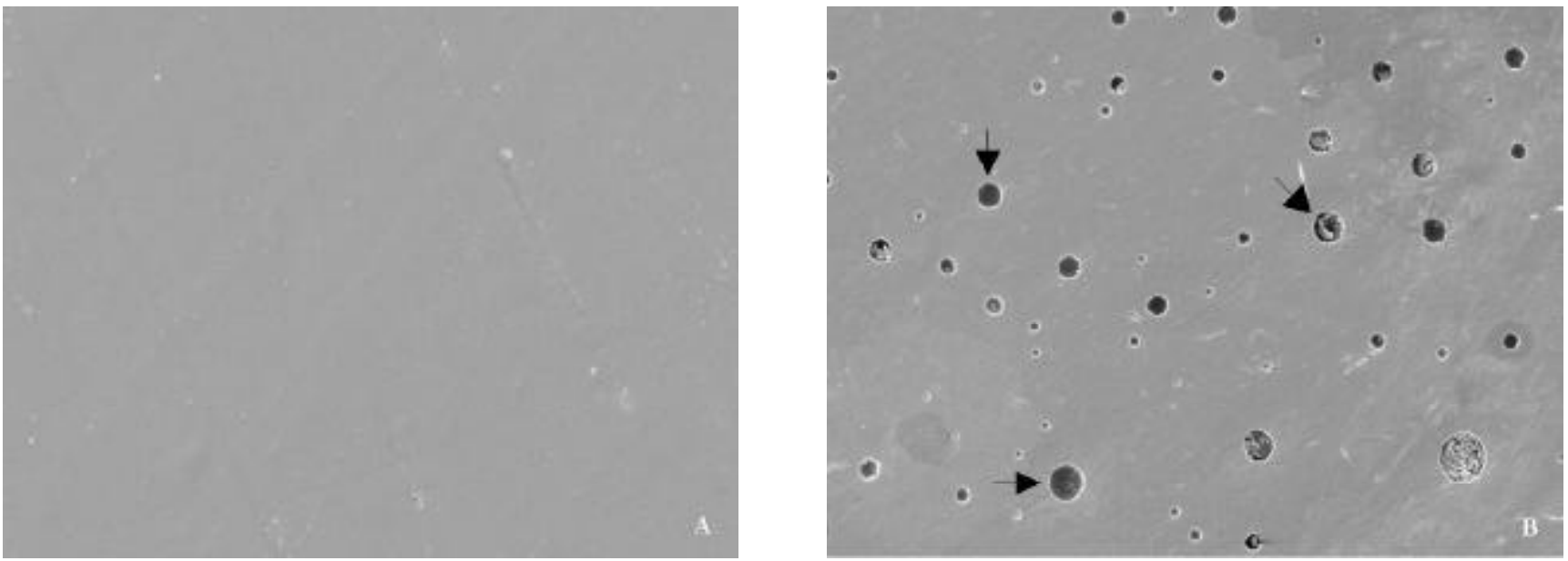

FIGURE 1- A110 conventional composite: (A) after polishing with Sof-Lex discs and before the mechanical toothbrushing test; (B) after the mechanical toothbrushing test. The arrows show the surface porosities of the composite sample. Original magnification $2500 x$
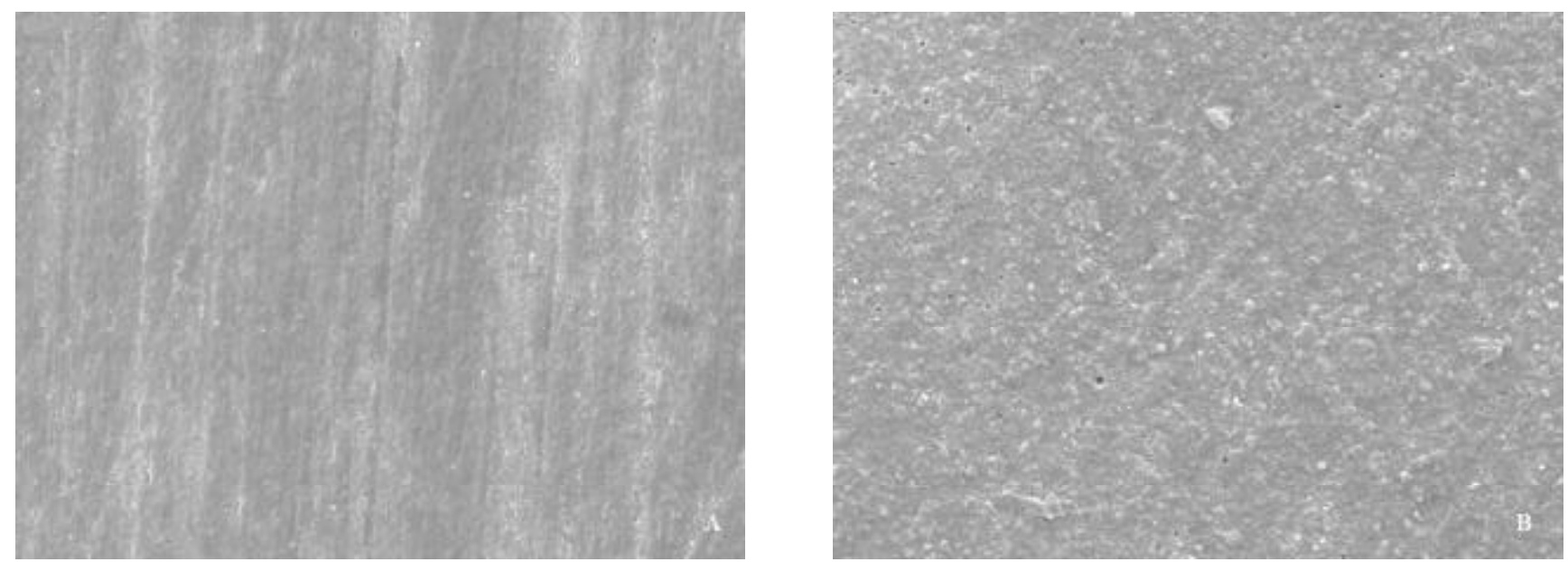

FIGURE 2- Admira ORMOCER composite: (A) after polishing with Sof-Lex discs and before the mechanical toothbrushing test; (B) after the mechanical toothbrushing test. Original magnification $2500 \mathrm{x}$
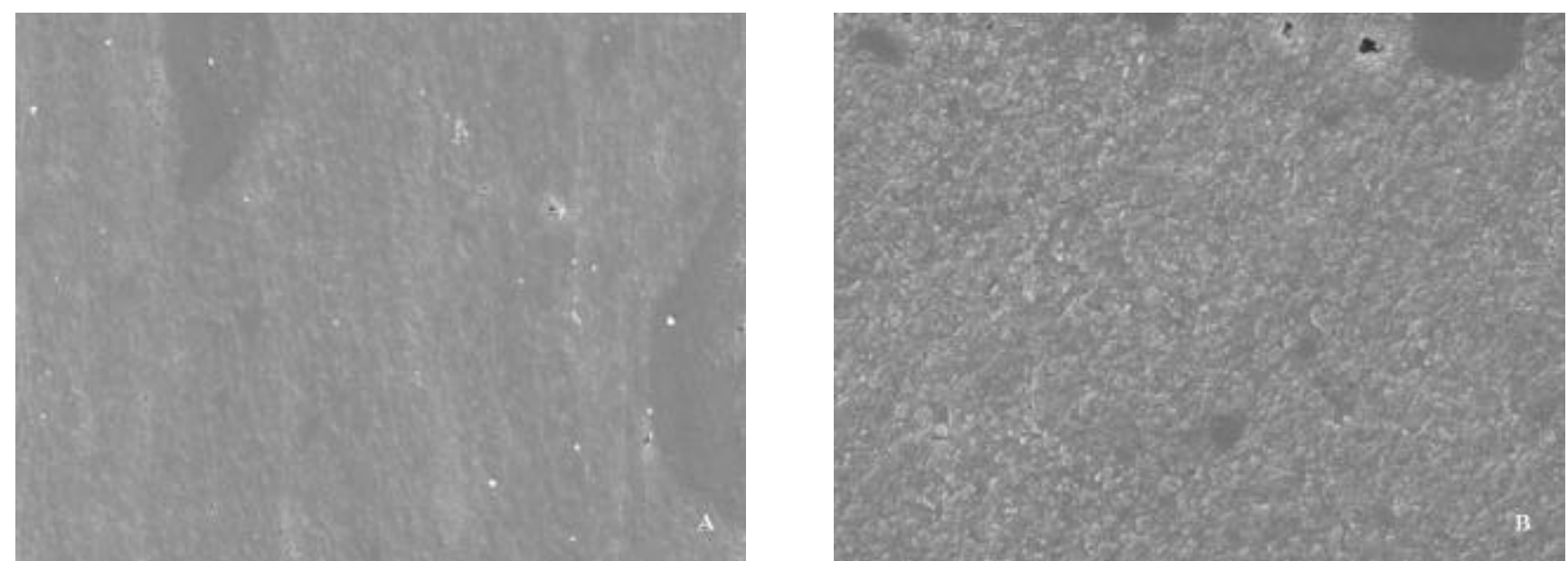

FIGURE 3- Definite ORMOCER composite: (A) after polishing with Sof-Lex discs and before the mechanical toothbrushing test; (B) after the mechanical toothbrushing test. Original magnification $2500 \mathrm{x}$ 
composite when compared to the conventional materials, due to the characteristic of its organic-inorganic resin matrix. The largest roughness is responsible for an undesirable loss of esthetics of the restoration, due to the loss of surface gloss and biological disadvantages ${ }^{12}$, causing dental plaque accumulation and increasing the risks of occurrence of caries and periodontal inflammation ${ }^{2}$.

However, this characteristic was not confirmed in this experiment, because the two Ormocer based composites, Definite and Admira, did not differ statistically from the Z250 composite, a conventional hybrid composite, after the polishing procedure. The Z250 composite presents a similar concentration of fillers compared to the Definite and Admira composites (Table 1), and the medium size of the filler particles is also similar $(0.7 \mathrm{~mm}$ to $1.0 \mathrm{~mm})$. This resulted in no difference in the surface roughness between the three mentioned materials, despite the modified organic matrix of the Ormocer-based composites. The conventional microfilled A110 composite presented the smallest values of surface roughness before toothbrushing, with a statistical difference compared to the Admira composite. The ability of a microfilled composite to present a lower surface roughness after polishing is its largest advantage, possibly related to the size of the extremely small filler particles $(0.04 \mathrm{~mm})$ and some degree of matrix protection ${ }^{4-10}$. However, no statistical difference was found between the composite A110 and the composites Z250 and Definite in this study (Table 2 in column). Swartz et al ${ }^{11}$ have also concluded that microfilled resins were less resistant to wear by toothbrushing and abrasives than the hybrid composite resins.

The effect of the mechanical toothbrushing test on the surface of the composites employed can be verified on Table 2. The test was accomplished in a total of 30,000 cycles, corresponding to an average of a 2 -year toothbrushing period in vivo ${ }^{1}$, and caused a significant increase in the surface roughness of all composites employed. The Definite and Admira composites presented an increase in the surface roughness of 37 and $62 \%$ respectively, and the conventional composites Z250 and A110, 77 and 134\%, respectively. The highly significant increase in the surface roughness of the composite A110 (134\%) is related to the emergence of porosities in the surface of this material after the mechanical toothbrushing test (Fig 1). The porosities presented a medium diameter of $40 \mathrm{~mm}$ and were found in 7 out of the 8 samples prepared with this material. The emergence of these porosities is possibly related to the easier incorporation of air in this composite. All samples were prepared in the same way and the presence of porosities could also be verified in other samples of different materials used, though in a much lower number and diameter compared to that found in material A110. Therefore, even though the composite A110 presents advantageous characteristics as to polishing properties and consequent surface smoothness, the emergence of a great number of porosities caused the increase in the roughness verified in this material. No statistical differences were found in none of the four materials used after the mechanical toothbrushing test. According to Bollen et al ${ }^{2}$, a surface roughness value equal or higher than $0.2 \mathrm{~mm}$ leads to accumulation of dental plaque, increasing the risk of caries and periodontal inflammation. In the present study, none of the materials analyzed presented a mean value of surface roughness equal or higher than $0.2 \mathrm{~mm}$ (Table 2 ), thus the number of cycles used in the study $(30,000$ cycles) was not enough to produce a roughness that would bring disadvantages from an esthetic and biological standpoint. However, in an in vivo situation, variables other than toothbrushing can cause wear of the composites. For example, temperature changes can cause tensile stress in the restoration, because of differences in the thermal expansion coefficients between the matrix and the filler ${ }^{6-13}$. Occlusal wear may also cause loss of material during mastication ${ }^{13}$. All these parameters may modify the values of surface roughness found.

From the results obtained in this study, it may be conclude that the Ormocer-based composites did not present statistical differences as to the surface roughness of the conventional composite Z250, before or after the mechanical toothbrushing test, despite of the organic-inorganic matrix of the Ormocer composite. The conventional microfilled composite A110 presented a surface roughness statistically inferior to the composite Admira before toothbrushing. However, no statistical differences were found after the mechanical toothbrushing test. Complementary studies should be accomplished to confirm
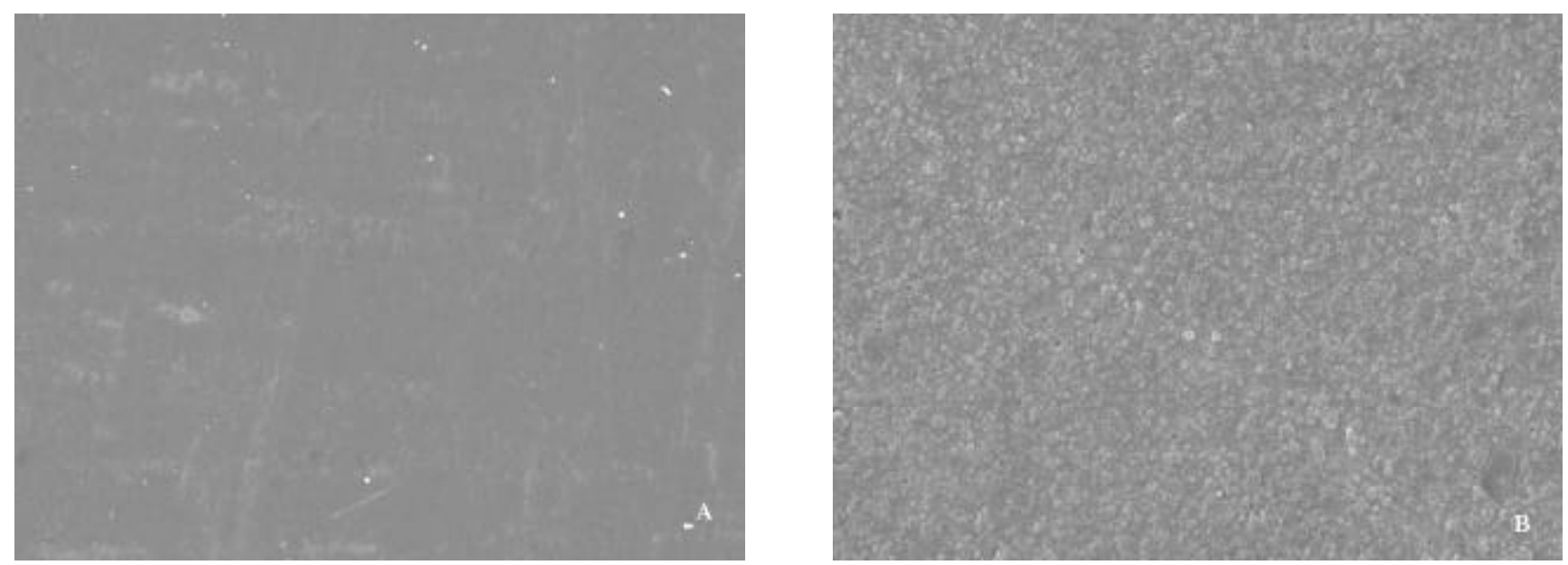

FIGURE 4- Z250 conventional composite: (A) after polishing with Sof-Lex discs and before mechanical toothbrushing test; (B) after mechanical toothbrushing test. Original magnification $2500 \mathrm{x}$ 
possible advantageous properties of the Ormocer-based composites when compared to conventional composites.

\section{ACKNOWLEDGEMENTS}

The authors thank Colgate (Brazil) for supplying the toothbrushes used in this study.

\section{RESUMO}

O objetivo deste estudo foi avaliar a rugosidade superficial antes e após ensaio de escovação de dois compósitos a base de Ormocer e compará-los a compósitos a base de sistemas monoméricos tradicionais. O estudo comparou as marcas Admira e Definite com os compósitos baseados em sistemas de monoméricos tradicionais (Bis-GMA, Bis-EMA, UEDMA e TEGDMA): Z250 e A110. Oito amostras de cada material com $4 \mathrm{~mm}$ em diâmetro por $2 \mathrm{~mm}$ em altura foram confeccionadas em uma matriz metálica rosqueável. Depois de 24 horas, as amostras foram submetidas a polimento e análise da rugosidade superficial inicial $(\mathrm{Ra}, \mu \mathrm{m})$ através de um profilômetro antes do ensaio de escovação mecânica (30.000 ciclos). Após o ensaio de escovação as amostras foram levadas mais uma vez ao profilômetro para mensuração da rugosidade superficial final. Os resultados foram submetidos a ANOVAe ao teste de Tukey (5\%). O compósito Admira apresentou a maior rugosidade superficial antes do ensaio de escovação mecânica $(0,132 \mu \mathrm{m})$, média estatisticamente superior ao compósito A110 $(0,082 \mu \mathrm{m})$. Os compósitos Definite $(0,110$ $\mu \mathrm{m})$ e Z250 $(0,105 \mu \mathrm{m})$ não apresentaram diferenças estatísticas entre si nem aos demais compósitos avaliados. Nenhuma diferença estatística foi observada após o ensaio de escovação entre os compósitos Definite $(0,178 \mu \mathrm{m}), \mathrm{Z} 250(0,187 \mu \mathrm{m})$, Admira $(0,181 \mu \mathrm{m})$, e A110 $(0,193 \mu \mathrm{m})$. Todos os compósitos apresentaram aumento estatisticamente significante da rugosidade superficial após o ensaio de escovação mecânica.

UNITERMOS: Compósito odontológico; ORMOCER; Rugosidade superficial.

\section{REFERENCES}

1- Aker JR. New composite resins: comparison of their resistance to toothbrush abrasion and characteristics of abraded surfaces. J Am Dent Assoc 1982 Oct; 105(4): 633-5.

2- Bollen CML, Lambrechts P, Quirynen M. Comparison of surface roughness of oral hard materials to the threshold surface roughness for bacterial plaque retention: A review of the literature. Dent Mater 1997; 13(4): 258-69.

3- Cannon ML, Marshall Jr GW, Marshall SJ, Cooley RO. Surface resistance to abrasion of performed laminate resin veneers. J Prosthet Dent 1984 Sep; 52(3): 323-30.
4- Jorgensen KD, Asmussen E. Occlusal abrasion of a composite restorative resin with ultra-fine filler. An initial study. Quintessence Int 1978 Jun; 9(6): 73-8.

5- Kawai K, Iwami Y, Ebisu S. Effect of resin monomer composition on toothbrush wear resistance. J Oral Rehabil 1998 Apr; 25(4): 2648.

6- Kusy RP, Leinfelder KF. Pattern of wear in posterior composite restorations. J Dent Res 1977 May; 56(5): 544.

7- Manhart J, Kunzelmann KH, Chen HY, Hickel R. Mechanical Properties of new composite restorative materials. J Biomed Mater Res 2000; 53(4): 353-61.

8- Manhart J, Kunzelmann KH, Chen HY, Hickel R. Mechanical properties and wear behavior of light cured packable composite resins. Dent Mater 2000 Jan; 16(1): 33-40.

9- Moszner N, Salz U. New developments of polymeric dental composites. Prog Polym Sci, 2001; 26: 535-76.

10- Sulong MZ, Aziz RA. Wear of materials used in dentistry: A review of the literature. J Prosthet Dent 1990 Mar; 63(3): 342-9.

11- Swartz ML, Moore BK, Phillips RW, Rhodes BF. Direct restorative resins - a comparative study. J Prosthet Dent 1982 Feb; 47(2): 163-9.

12- Tanoue N, Matsumara $\mathrm{H}$, Atsuta $\mathrm{M}$. Wear and surface roughness of current prosthetic composites after toothbrushing/dentifrice abrasion. J Prosthet Dent 2000 Jul; 84(1): 93-6.

13- Van Dijken JWV, Stadigh J, Meurman JH. Appearance of finished and unfinished composite surfaces after toothbrushing. A scanning electron microscopy study. Acta Odontol Scand 1983 Dec; 41(6): 377-83.

14- Whitehead SA, Shearer AC, Watts DC, Wilson NHF. Surface texture changes of a composite brushed with "tooth whitening" dentifrices. Dent Mater 1996 Sep; 12(5): 315-8.

15- Wolter H. Bulk-ORMOCERs and ORMOCER composites. Fraunhofer-Institut für Silicatforschung (ISC) - Annual Report 1995; 45-51.

Recebido para publicação em: 06/06/2003

Enviado para reformulações em: 15/07/2003

Pronto para publicação em: 26/09/2003

Adress for correspondence:

Prof. Dr. Mário Alexandre Sinhoretti

Faculdade de Odontologia de Piracicaba - UNICAMP

Departamento de Odontologia Restauradora

Av. Limeira, 901

13414-018 PIRACICABA S.P.

e-mail: sinhoret@fop.unicamp.br

Fone: (19) 3412-5374

Fax: (19) 3412-5218 